\title{
КЛАССИФИКАЦИЯ СТРАТИГРАФИЧЕСКИХ ПРОБЕЛОВ И СЕДИМЕНТАЦИОННЫХ ПЕРЕРЫВОВ В ПАЛЕОЗОЕ ПРИБАЛТИКИ
}

После завершения большого этапа работ по разработке и унифицированию стратиграфических схем (Решения..., 1978) и по составлению комплекса обобщающих региональных геологических карт перед геологами Прибалтики встала задача о системном подходе к изучению прерывистости осадконакопления. На фоне достигнутого успеха в области стратиграфических и фациальных исследований потребность в изучении перерывов выступает особенно резко. В результате многолетней стратиграфической работы мы ныне довольно хорошо представляем себе распространение осадочных толщ, особенности их формирования в седиментационных бассейнах, но о том, что происходило в промежутках существования этих бассейнов, мы знаем еще сравнительно мало. А знать это необходимо, так как именно с перерывами в образовании осадочных толщ теснейшим образом связаны переотложение больших масс ранее отлагавшихся осадков, мобилизация дополнительных порций полезных элементов, следовательно, и процессы формирования многих полезных ископаемых. Отметим хотя бы Прибалтийские фосфориты и бурые оолитовые руды железа в разрезе кембрия, образование которых теснейшим образом связано с периодами предшествующих перерывов в осадконакоплении.

С другой стороны, немаловажен и теоретический аспект изучения перерывов, в частности оценка глубины размыва в реальных осадочных комплексах. Без какого-либо достоверного материала по этой части мы можем легко ошибиться в любых палеогеографических реконструкциях геологического прошлого.

Исходя из этих обстоятельств, в Институте геологии АН ЭССР с 1983 г. разрабатывается тема по изучению перерывов в разрезе палеозоя Прибалтики. Проблема эта многосторонняя и сложная, ее разным аспектам посвящена представительная геологическая литература. Многие важные вопросы, связанные с перерывами, рассмотрены в трудах Р. Ф. Геккера (1960), Д. В. Наливкина (1974), В. С. Яблокова (1973), И. А. Вылцана $(1969,1980)$ и др. Из зарубежных коллег следует прежде всего отметить работы Р. Шрока (1950), В. Яануссона (Јаanusson, 1961), Х. Хединга (Hadding, 1958), M. Вейса (Weiss, 1958), К. Данбара и Дж. Роджерса (1962) и др. Среди первых большое внимание на перерывы уделял академик АН ЭССР К. К. Орвику (Orviku, 1940, 1961; Орвику, 1962), который привел детальные описания и изображения разнообразных поверхностей перерывов в известняках нижнего и среднего ордовика Северной Әстонии, ставшими сейчас классическим примером их литологического изучения. 
Однако, несмотря на имеющуюся литературу, в настоящее время нет как обобщающей сводки по перерывам, так и их удовлетворительной классификации, позволяющей провести «инвентаризацию» перерывов в Прибалтийском разрезе, независимо от их фиксации в самых различных геологических обстановках и осадочных формациях. Поэтому разработка такой классификации представляла для нас первостепенную задачу, однако в этой связи мы сразу же сталкивались с определенными терминологическими трудностями.

Дело в том, что основной термин этой области - перерыв - имеет несколько значений. Этимологически он выражает прежде всего прекращение, приостановление какого-то действия, в нашем случае осадконакопления, а также промежуток времени, на которое прекращается действие. Следовательно, «перерыв» в таком истолковании понятие абстрактное, временно́е и хорошо обозначает тот период, когда осадконакопление как процесс был почему-то прерван и заменен процессами денудации.

С другой стороны, при изучении конкретных разрезов, в частности поверхностей перерывов, мы всегда определяем объем отсутствующих в разрезе слоев и называем этот пробел также перерывом, исходя из второго значения термина «перерыв»: разрыв, разъединение чего-либо на части, пространство, разделяющее что-либо расположенное сплошной массой, пластом и т. д.

Тем самым мы вносим явную нечеткость в научные термины, обозначая одним и тем же словом как причину явления (прекращение процесса осадконакопления), так и ее следствие (отсутствие какой-то части разреза). Это, на наш взгляд, очень нежелательно, но таких примеров использования этого термина в геологической литературе существует, к сожалению, достаточно.

Как обозначить реально отсутствующие в разрезе отложения одним словом? Оказывается такого, всеми однозначно понимаемого, в нашей терминологии нет. В литературе применяются выражения - перерыв в отложениях, перерыв в разрезе, перерыв в последовательности слоев, пропуск слоев, стратиграфический перерыв, стратиграфический пробел, несоответствие, несогласие и многие другие. Как было уже отмечено, применение слова «перерыв» с каким-либо объясняющим прилагательным все же нежелательно. Из-за краткости и большей ясности внимание привлекают два последних термина. Однако как «несоответствие», так и «несогласие» не относятся к отсутствующей части разреза, а характеризуют особенности залегания пород ниже и выше поверхности перерыва - т. е. являются позднейшим структурным выражением события, обусловливающего отсутствие слоев. Слово «несогласие» прочно вошло в геологическую литературу именно в таком понимании и нашло применение также в платформенных областях, где угловые несогласия обычно невелики и малозаметны. Для этих районов появились термины «скрытое» и «параллельное» несогласие, а также близкое им по содержанию «несоответствие», однако все они таят в себе структурно-геологический смысл и поэтому не приемлемы для нашего случая.

Для обозначения отсутствия слоев в конкретном разрезе кажется наиболее подходящим термин «пробел» или словосочетание «стратиграфический пробел», который мы и предлагаем применять параллельно с временны́ понятием «перерыв» при изучении прерывистости процесса осадкообразования. При этом перерыв - процесс, действие, причина, а пробел - последствие, реальный результат первого. К сожалению, термин «пробел» не нашел пока широкого применения в геологической практике, и нам кажется потому, что геологи не всегда дают себе отчет, о чем идет речь. Это и привело к излишнему применению хорошего термина «перерыв», чего приходится только сожалеть. 
Нам представляется, что перерыв в осадконакоплении - это наша конечная цель изучения - выявление истинного временного интервала, на протяжении которого накопления осадков не происходило и был возможен размыв подстилающих отложений. Понятие это явно временно́е. Другой термин - стратиграфический пробел (пропуск слоев в последовательности наслоения, отсутствие осадков) - это обозначение реального объекта в геологическом разрезе, через изучение которого мы и достигаем своей конечной цели - выясняем длительность и природу перерыва в осадконакоплении. Пробел в разрезе - это отсутствующее геологическое тело в непрерывной последовательности слоев и его также удобнее всего выражать в единицах геологического времени, однако эта мера в данном случае не идентична времени самого перерыва в осадконакоплении, так как включает в себя и время формирования тех толщ, которые размыты во время данного перерыва. Кроме того, реальный пробел в разрезе может быть охарактеризован и другими признаками: например, наличием базального конгломерата в вышележащих отложениях или коры выветривания в нижележащих, резким изменением литологического характера слоев выше и ниже поверхности перерыва, особенностями выявления углового несогласия и др.

Поэтому мы предлагаем охарактеризовать перерыв в осадконакоплении только таким параметром как длительность - т. е. реальным временем его существования, а стратиграфический пробел (реально отсутствующую часть в разрезе) охватом или объемом, Последние могут быть выражены также в единицах времени (напр., отсутствуют верхи силура или низы девона), однако должны быть всегда охарактеризованы и набором отсутствующих био- или литостратиграфических единиц, т. е. комплексов отложений (напр., отсутствуют те или др. свиты).

Естественно, что в практической речи эта разница нередко забывается или стирается, тем более, что разница между длительностью перерыва и охватом возникшего реального пробела является ощутимым лишь для крупных перерывов. Для мелких седиментационных перерывов, не сопровождавшихся существенным размывом, эти понятия близки по своим объемам. Однако в случаях, когда мы касаемся вопросов специально о перерывах, эта двусмысленность слова перерыв должна быть устранена и вносить определенную ясность должно понятие пробел.

Если вернуться к проблеме иерархизации и классификации перерывов, то очевидно, что для перерывов в осадконакоплении применим только один параметр - время. На основе длительности самого перерыва мы можем его назвать несущественным, малым, средним, крупным или даже громадным и выделить среди них соответствующие классы. При этом необходимо иметь в виду, чтобы основной его показатель - длительность - был определен с достаточной точностью.

Принципиально так же обстоит дело и с пробелом - реально отсутствующими в разрезе отложениями. Однако кроме охвата по шкале геологического времени (или объема геологических подразделений разного ранга) здесь могут быть учтены и некоторые другие характеристики, в частности структурно-геологические и литологические, признаки выветривания подошвы и др. Важной является резкость литологического характера пород ниже и выше поверхностей перерыва, а также сама морфология поверхности перерыва, на которую обратили внимание многие авторы (Orviku, 1940, 1961; Орвику, 1960; Геккер, 1960; Эйнасто, 1964 и др.). В характеристике пробелов через поверхности перерывов могут быть использованы и элементы классификации несогласий, которые хорошо разработаны А. А. Богдановым (1949) и А. Қ. Башариным (1961). 


\begin{tabular}{|c|c|c|c|}
\hline Название & Охват, & объем & Характерные особенности \\
\hline Мегапробел & $\begin{array}{l}500-100 \text { млн. } \\
\text { лет }\end{array}$ & $\begin{array}{l}\text { Отсутствует ряд } \\
\text { систем - отло- } \\
\text { жений основ- } \\
\text { ного геотекто- } \\
\text { нического } \\
\text { цикла. } \\
\text { Отсутствуют } \\
\text { отложения } \\
\text { большого этапа, } \\
\text { обычно несколь- } \\
\text { ко систем. }\end{array}$ & $\begin{array}{l}\text { Региональная выдержанность, ясное угло- } \\
\text { вое несогласие и изменение литологиче- } \\
\text { ского характера отложений на уровне по- } \\
\text { верхности перерыва может иметь регио- } \\
\text { нальное распространение, но часто огра- } \\
\text { ничивается отдельными структурами. } \\
\text { Угловое несогласие, изменение литологи- } \\
\text { ческого характера отложений. }\end{array}$ \\
\hline $\begin{array}{l}\text { Макро- } \\
\text { пробел }\end{array}$ & $\begin{array}{l}100-10 \text { млн. } \\
\text { лет }\end{array}$ & $\begin{array}{l}\text { Отсутствуют } \\
\text { отделы, ярусы } \\
\text { или группы } \\
\text { горизонтов. }\end{array}$ & $\begin{array}{l}\text { Распространяется обычно в пределах от- } \\
\text { дельных тектонических блоков. Часто на- } \\
\text { блюдается угловое несогласие, по крайней } \\
\text { мере изменение структурного плана осад- } \\
\text { конакопления. Литологический характер } \\
\text { отложений может изменяться несущест- } \\
\text { венно. }\end{array}$ \\
\hline $\begin{array}{l}\text { Мезопробел } \\
\text { П о д - } \\
\text { к л а с с ы: } \\
\text { олигопро- } \\
\text { бел }\end{array}$ & $10-1$ млн. лет & $\begin{array}{l}\text { Отсутствует } \\
1-2 \text { горизонта } \\
\text { или часть их. }\end{array}$ & $\begin{array}{l}\text { Распространяется обычно в пределах се- } \\
\text { диментационного бассейна. Четкого угло- } \\
\text { вого несогласия, как правило, не наблю- } \\
\text { дается, сохраняются основные климати- } \\
\text { ческие и палеотектонические условия } \\
\text { осадконакопления - не меняется литоло- }\end{array}$ \\
\hline $\begin{array}{l}\text { парвапро- } \\
\text { бел }\end{array}$ & $1-0,1$ млн, лет & & $\begin{array}{l}\text { гический характер отложений. На боль- } \\
\text { ших площадях можно наблюдать измене- } \\
\text { ния структурного плана. }\end{array}$ \\
\hline $\begin{array}{l}\text { Микропро- } \\
\text { бел }\end{array}$ & $\begin{array}{l}100000- \\
1000 \text { лет }\end{array}$ & $\begin{array}{l}\text { Отсутствует } \\
\text { не более } \\
\text { объема пачки. } \\
\text { Нередко } \\
\text { отсутствующая } \\
\text { часть разреза } \\
\text { не установима } \\
\text { обычными } \\
\text { стратиграфиче- } \\
\text { скими мето- } \\
\text { дами. }\end{array}$ & $\begin{array}{l}\text { Распространяется в пределах фациальной } \\
\text { зоны. Поверхность перерыва обычно чет- } \\
\text { кая, нередко с признаками размыва. Угло- } \\
\text { вого несогласия и принципиальной смены } \\
\text { условий осадконакопления не наблю- } \\
\text { дается. }\end{array}$ \\
\hline Нанопробел & $1000-1$ лет & $\begin{array}{l}\text { Отсутствующая } \\
\text { часть разреза } \\
\text { не устанавли- } \\
\text { ваемая. }\end{array}$ & $\begin{array}{l}\text { Распространение локальное. Поверхности } \\
\text { перерывов нередко отчетливые и рельеф- } \\
\text { ные, часто совпадают плоскостями наслое- } \\
\text { ния. }\end{array}$ \\
\hline Пикопробел & $\begin{array}{l}\text { Внутригодовые } \\
\text { периоды }\end{array}$ & $\begin{array}{l}\text { Проявления } \\
\text { седиментацион- } \\
\text { ного значения: } \\
\text { местные размы- } \\
\text { вы в результате } \\
\text { сезонных штор- } \\
\text { мов, приливов- } \\
\text { отливов, } \\
\text { оползней; фор- } \\
\text { мирование } \\
\text { косой сло- } \\
\text { истости. }\end{array}$ & $\begin{array}{l}\text { Распространение узко локальное. Местные } \\
\text { несогласия слойков, швы косослоистых } \\
\text { серий, четкие плоскости наслоения и др. }\end{array}$ \\
\hline
\end{tabular}

Однако для анализа реальных пробелов в большом разнофациальном разрезе единственным универсальным критерием иерархизации служит именно временной охват отсутствующих отложений, что позволяет сравнивать между собой близкие пробелы в различно построенных 
осадочных толщах. Такой подход заставляет рассматривать пробелы как стратиграфические объекты и тем самым привлекает для их изучения стратиграфические методы. Это особенно важно для Прибалтийского региона, где литологические, фациальные, стратиграфические и палеонтологические исследования традиционно тесно переплетались между собой в геологических работах и тем самым обеспечивали комплексность анализа материала. Отметим еще, что от основной временно́й характеристики пробелов нетрудно перейти к использованию их при анализе цикличности осадконакопления и при формационном анализе. Резкость изменения литологического характера пород на рубежах поверхностей перерывов, как и структурные взаимоотношения пород кровли и подошвы целесообразно использовать лишь в качестве дополнительных критериев, имеющих большие колебания, но все же коррелирующиеся в общих чертах с классами иерархизации пробелов по их крупности во временно́й шкале.

Пример такой классификации пробелов и представлен в таблице.

При разработке основных подразделений данной классификации мы старались использовать градации, которые частично применяются в иерархизации разнопорядковых циклов в отечественной геологической практике (Афанасьев, 1977). Для обозначения выделенных классов была привлечена номенклатура международной метровой системы с соответствующими латинскими или греческими приставками к основному слову. Однако теперь возникает новая трудность - получается нежелательное словосочетание интернациональной приставки с русским словом. Заменить принятую иерархию: гига, мега, макро, мезо, микро, нано и пико с однозначно применяемыми русскими словами нам кажется пока весьма сложным, однако небесперспективным.

В эстонском языке все эти трудности легко преодолимы: имеются разнокорневые слова для собственного перерыва (katkestus) и для стратиграфического пробела (lünk), нет и особенных затруднений прибавлять им слова величинной градации (микро, макро и др.), хотя и это не очень рекомендуется филологами. Не исключается и переход от иностранных приставок к соответствующим эстонским гомологам.

В классификационной схеме стратиграфических пробелов по материалу Прибалтийского разреза предлагаются выделить следующие классы.

1. Гигапробел охватывает отложения целой группы систем, объем которых либо соответствует, либо существенно превышает объем основных глобальных геотектонических циклов - каледонского, герцинского, альпийского. Следовательно, при гигапробеле в разрезе отсутствуют отложения с длительностью образования 500 млн. лет и более.

Естественно, что гигапробел характеризуется явным угловым несогласием, резким изменением литологического характера пород выше и ниже его, а также обширным площадным распространением. Если перечисленных признаков не наблюдается, то это явно исключение, а не правило. В Прибалтике можно выделить два гигапробела - предвендский и последевонский-дочетвертичный.

2. Мегапробел характеризуется отсутствием нескольких систем и охватывает в стратиграфическом смысле 100-500 млн. лет. Этому классу пробелов присуще также угловое несогласие и резкое изменение литологии пород на рубеже поверхности перерыва. Примером мегапробела может служить отсутствие осадков между ордовиком и девоном в районе Локновской структуры. Принципиально гига- и мегапробелы имеют сходство и в практической работе могут быть рассмотрены вместе в составе группы крупных пробелов. 
3. Макропробел имеет уже большее значение в практической работе. В этом случае в разрезе отсутствуют отделы, ярусы или группы горизонтов. Временной охват отсутствующих отложений, на наш взгляд, целесообразно принимать в интервале $10-100$ млн. лет. На уровне поверхности перерыва в данном случае наблюдается, как правило, угловое несогласие, а по площади - заметное изменение структурного плана. В отличие от пробелов более высокого ранга климатический фактор осадконакопления и, следовательно, литологический характер пород могут изменяться несущественно.

В качестве примера указываем на отсутствие отложений между средним кембрием и тремадоком на большой площади Северной Прибалтики.

4. Мезопробел характеризуется отсутствием одного горизонта или его части. Продолжительность $0,1-10$ млн. лет.

Резкого углового несогласия обычно не наблюдается, сохраняется также основной характер осадконакопления. На большой территории может выявляться изменение структурного плана осадкообразования. Поверхности перерыва обычно отчетливые. Примеры в разрезе Прибалтики многочисленны, но наиболее характерны они для нижнего кембрия, где пробелы данного ранга отчетливо разделяют осадочные серии и имеют региональное распространение.

Есть основание предполагать, что выделяемый ранг мезопробела является основным объектом исследования в геологических разрезах, а при этом может возникнуть необходимость его подразделения на более мелкие категории, тем более, что предложенное возрастное ограничение $(0,1-10$ млн. лет) не очень удовлетворяет стройности классификации. Для уточнения требований к мезопробелу потребуется накопление определенного опыта, ввиду чего этот вопрос можно оставить сейчас открытым. Отметим лишь, что предлагаемая классификация позволяет разные решения: разделение мезопробела в дальнейшем на подклассы или выделение на стыках его новых классов. Терминологически подходящими могут оказаться понятия олигопробел $(1-10$ млн. лет) и парвапробел $(0,1-1$ млн. лет).

5. Микропробел отличается отсутствием части разреза не более пачки. Нередко выпадающая часть разреза не установима обығшыми стратиграфическими методами. Часто отмечается отчетливая поверхность перерыва, однако большая часть таких пробелов относится к труднодиагностируемым («скрытым»).

Угловое несогласие обычно отсутствует, несущественно меняется также характер отложений. Длительность пробела составляет ориентировочно $1000-100000$ лет.

6. Нанопробел относится уже к чисто седиментологическим явлениям - отсутствующая часть разреза неопределима стратиграфическими методами. Временной охват пробела измеряется годами.

Поверхности на рубеже перерыва могут быть отчетливые, чаще всего они маркируются контактами слоев разного состава. «Скрытые» нанопробелы обычно остаются невыявленными.

7. Пикопробел - это уже элементарная единица седиментационного значения, которая характеризует внутрислоевые перерывы - швы наклоннослоистых серий, оползни, размывы приливов-отливов и сезонных бурей и уровни биотурбации. Эти перерывы могут продолжаться меньше года.

Предложенная классификация принята нами за основу анализа про- 
белов в палеозойском разрезе Северной Прибалтики и уже первые попытки показали ее работоспособность. Полученный опыт мы попытаемся изложить в последующих сообщениях.

Для графического изображения выделяемых пробелов в обычных стратиграфических схемах мы предлагаем соответствующие обозначения, которые просто применимы (рисунок). Для наиболее крупных пробелов первых четырех классов это регулярные вертикальные линии, длина которых соответствует конкретному охвату пробела в данном разрезе, а характер линии - классу пробела. Стратиграфический охват микропробелов обычно не определяется, предлагаются немасштабное ғоризонтально-линейные изображения с небольшими элементами вертикальной разрисовки, соответствующие морфологическим особенностям данной поверхности перерыва. Пикопробелы (всегда узколокальное явление) мы предлагаем обозначать отдельными изолированными знаками, сводимыми, при надобности, в одну прерывистую линию. Естественно, что при этом учет и регистрация мелких пробелов-перерывов (нано, пико) осуществимы только при специальных работах и больших масштабах изображения. Однако выделением этих классов созданы все условия для их регистрации и системного изучения в дальнейшем.

В качестве переходного между

a
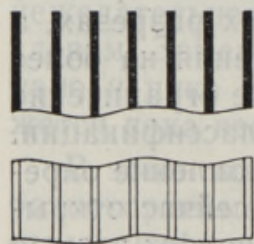

META

ГUГA

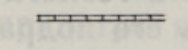

MUKDO
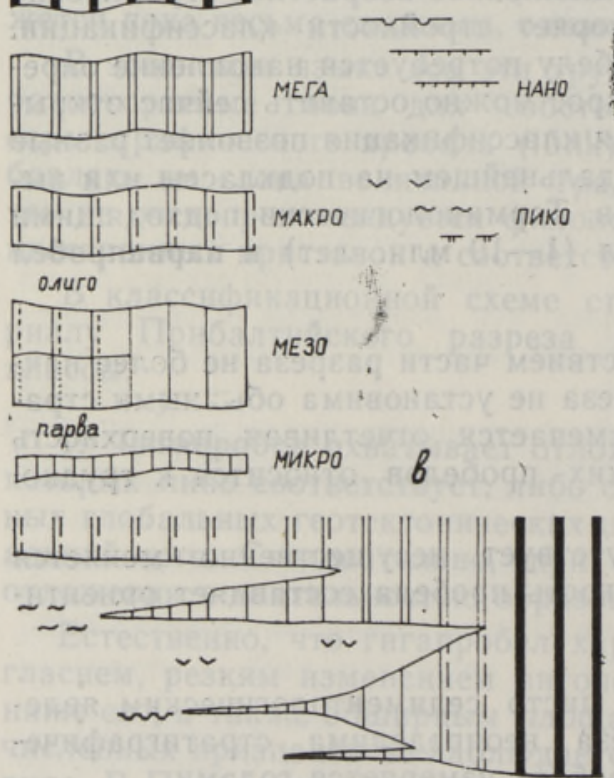
крупными и мелкими пробелами является микропробел, стратиграфический объем которого иногда необходимо показать и в масштабе. Для него предлагается густая вертикальная заштриховка, которая легко трансформируемая как в масштабную, так и в линейную форму (рисунок, $a, \sigma)$.

Предлагаемое обозначение пробелов различного ранга на стратиграфических схемах и в специальных работах по изучению пробелов. $a-$ масштабные, б - линейные, в - пример комбинированного использования.

В пользу использования предлагаемого изображения пробелов на стратиграфических схемах говорит еще и то, что эти условные знаки позволяют показать плавные переходы по латерали одного класса пробела в другой, что обычно наблюдается в геологических разрезах с выпадением отдельных стратиграфических подразделений на больших площадях.

В связи с закономерным латеральным переходом пробела одного класса в другой возникает необходимость внести еще дополнительный 
параметр горизонтальной выдержанности пробела, или же построить даже соответствующую рубрикацию всех выделенных пробелов. Нам кажется, что второй вариант все же нецелесообразен, так как даже мелкие по охвату пропуски слоев (нано- и микропробелы) могут занимать весьма различные пространства по площади. Лучше, на наш взгляд, оставлять этот признак в качестве важной характеристики каждого пробела в отдельности и не вносить его в ранг определяющего параметра классификации.

Естественно, что пробелы, как и многие другие признаки осадочных толщ могут быть узколокальными, региональными и даже межконтинентальными. При этом выдержанность по площади весьма хорошо коррелируется с классом пробела. Так гига-и мегапробелы в платформенных условиях без контрастного дробления осадочного чехла на отдельные тектонические блоки являются всегда региональными. Макропробелы в большей части ограничиваются отдельными структурно-фациальными районами бассейнов осадконакопления, сравнительно редко выходя за их границы. Мезопробелы, судя по материалам палеозоя Прибалтики, обычно связаны с отдельными зонами единого бассейна осадконакопления, а микро- и нанопробелы характерны определенным фациям в бассейне. Именно последнее обстоятельство - связь мелких пробелов с отдельными фациями бассейнов, - имеет большое значение для понимания седиментологических процессов и заслуживает особого внимания в литологин. Вполне вероятно, что накапливающийся в дальнейшем материал по мелким пробелам создаст основу для выработки дополнительных классификационных схем, однако в данное время мы таким материалом еще не располагаем.

В данной классификации мы не использовали ряда известных уже терминов в практике изучения перерывов, таких как, например, диастема (Barrel, 1917). Мы считаем, что для характеристики отдельных аспектов формирования пробелов этот термин, как и многие другие, имеет право на самостоятельное существование, аналогично достаточно четко разработанной классификации несогласий - структурных выражений перерывов по условиям залегания контактирующих на поверхности перерыва слоев. Однако вводить такие термины в классификационную схему, построенную по определенному принципу, не следует - это привносит нечеткости и, в целом, затрудняет использование классификации.

Отметим еще, что выбирая основным параметром классификации пробелов их охват, выраженный через стратиграфические подразделения в единицах геологического времени, мы создадим путь для перехода к классыфикации истинных перерывов после того, как их длительность будет определена. При этом потребуется лишь несущественная переработка основного каркаса группировки пробелов, но сохранится та же схема иерархизации объектов, будет использована своя номенклатура, сократится описательная характеристика перерывов. Естественно, что для мелких пробелов и перерывов классификационные рубрики в основном совпадают. Для крупных классов сохраняются существенные различия, однако путем использования на стратиграфических схемах предложенного графического изображения пробелов можно прямо на них нанести также промежутки истинных перерывов, используя для этого специальные линии или дополнительный крап. Такне схемы станут, на наш взгляд, способом регистрации информации о перерывах в осадконакоплении, и во многом содействуют составлению достоверных палеогеографнческих карт.

И наконец, наступило, по-видимому, время для включения определенных положений о пробелах и перерывах в Стратиграфический кодекс $\mathrm{CCCP}$, чтобы этот регламентирующий документ мог послужить руковод- 
ством и в данной области исследования. Предлагаемая нами схема иерархизации пробелов может быть рекомендована для этой цели лишь после прохождения стадии ее испытания на конкретном геологическом материале, однако мы надеемся, что путь к такому решению этой классификацией все же подготавливается.

\title{
ЛИТ Е Р А Т У Р А
}

Афанасьев С. Л. Пульсы и циклы верхнемеловых отложений Большого Кавказа. - В кн.: Цикличность отложений нефтегазоносных и угленосных бассейнов. М., 1977, $177-190$.

Башарин А. К. Типы несогласного залегания слоев. - Геол. и геоф., 1961, № 9, 13-21.

Богданов А. А. Несогласия, их типы и значение их изучения. - Изв. АН СССР, сер. геол., 1949, № 2, 43-60.

Вылцан И. А. Опыт диагностики и оценки продолжительности скрытых перерывов в осадочных формациях. - Тр. Томского ун-та, 1969, 203, 75-85.

Вылцан $Н . A$. Методы выявления и оценки продолжительности явных и скрытых перерывов в осадконакоплении. - В кн.: Проблемные вопросы циклостратиграфии. Новосибирск, 1980, 132-143.

Геккер Р. Ф. Ископаемая фация гладкого каменного морского дна. (K вопросу о типах каменного морского дна). - Тр. Ин-та геол, АН ЭССР, 1960, V, $199-227$.

Данбар К., Роджерс Дж. Основы стратиграфии. М., 1962.

Наливкин Д. В. Проблемы перерывов. - В кн.: Этюды по стратиграфин. М., 1974, $10-21$.

Орвику К. К. Литофациальные особенности ордовикских горизонтов волхов $\left(\mathrm{B}_{\mathrm{II}}\right)$, кунда $\left(\mathrm{B}_{\mathrm{III}}\right)$ и азери $\left(\mathrm{C}_{\mathrm{I}} \mathrm{a}\right)$ в северной части Эстонской ССР. - Междунар. геол. конгр., XXI сессия. Докл. советских геологов. Пробл. 7. М.-И., 1960, 71-80.

Орвику K. К. О литостратиграфии волховского и кундаского горизонтов в Эстонии. Тр. Ин-та геол. АН ЭССР, 1960, V, 45-88.

Орвику K. K. О гальках в волховском $\left(\mathrm{B}_{\mathrm{II}}\right)$ и кундаском $\left(\mathrm{B}_{\mathrm{III}}\right)$ горизонтах нижнего ордовика Эстонни. - Тр. Ин-та геол. АН ЭССР, 1962, Х, 187-203.

Решения Межведомственного регионального стратиграфического совещания по разработке унифицированных стратиграфических схем Прибалтики, 1976. Л., 1978.

Шрок $P$. Последовательность в свитах слоистых пород. М., 1950.

Яблоков В. С. Перерывы в морском осадконакоплении и палеореки. М., 1973.

Эйнасто Р. Э. K вопросу о классификации и формировании поверхностей перерыва. В кн.: Литология палеозойских отложений Эстонии. Таллин, 1964, 124-131.

Barrel, J. Rhytms and the measurement of geological time. - Bull. Geol. Soc. Amer., $1917,28$.

Hadding, $H$. Hidden hiatuses and related phenomena. Some lithological problems. Kungl. Fysiogr. Sällskop. I. Lund Förhandl., 1958, 28, N 17, 159-171.

Jaanusson, V. Discontinuity surfaces in limestones. - Bull. Geol. Inst. Univ. Uppsala, $1961,40,221-241$.

Orviku, K. Lithologie der Tallinna-Serie (Ordovizium, Estland). - I Acta Univ. Tartu, 1940 A, N 36.

Orviku, $K$. Diskontinuiteetpinnad Volhovi ja Kunda lademes. - ENSV TA Loodusuurijate Selts. Geoloogiline kogumik, 1961, 16-23.

Weiss, M. Corrosion zones: a modified hypothesis of their origin. - J. Geochim. Petrol., $1958,28, \mathrm{~N} 4,486-489$.

\author{
Ннститут геологии \\ Академии наук Эстонской ССР \\ Поступила в редакцию \\ 19/IX 1985
}

\section{E. PIRRUS, R. EINASTO}

\section{BALTIKUMI VANAAEGKONNA SETTELUNKADE JA -KATKESTUSTE KLASSIFIKATSIOON}

Baltikumi unifitseeritud stratigraafilise skeemi väljatöötamine ja üldistavate regionaalsete geoloogiliste kaartide koostamine viimasel aastakümnendil on tinginud vajaduse edaspidi hoolikalt uurida ka settelünki läbilöigetes, et saada tervikulist pilti ala geoloogilisest arenguloost. Seni puudub vajalik klassifikatsioon lünkade süstemaatiliseks registreerimiseks erineva fatsiaalse ilmega settekompleksides. Artiklis tehakse katse koostada 
see Baltikumi vanaaegkonna läbilōike lünkade analüüsi baasil. Hierarhilise klassifikatsiooni pöhiparameetriks on valitud lünga stratigraafiline maht, mille järgi viimased reastatakse eri suuruskategooriateks. Selline võte on mugav eri järku lünkade kujutamiseks stratigraafilisel skeemil, samuti võimaldab see hiljem üle minna printsiibilt samalaadsele settekatkestuste klassifikatsioonile, mille põhiparameetriks võetakse aeg - katkestuse kestus.

Artiklis on näidatud, et venekeelses geoloogilises kirjanduses kasutatakse katkestusperioodi ja reaalselt eksisteeriva lünga jaoks sageli üht ja sama sõna, mis teeb vastava terminoloogia ebakindlaks ja raskendab rahuldava klassifikatsiooni koostamist. Tehakse ettepanek vastava terminoloogia korrastamiseks.

\section{E. PIRRUS, R. EINASTO}

\section{CLASSIFICATION OF SEDIMENTARY HIATUSES AND BREAKS IN THE PALEOZOIC OF THE EAST BALTIC AREA}

In the last decade the elaboration of a unified stratigraphical scheme for the East Baltic area and the compilation of generalizing regional maps have caused a need for a thorough study of sedimentary hiatuses in sections in order to get a complete picture about the geological development of the territory. A classification necessary for systematic registration of hiatuses in sedimentary complexes of a different facial character is still lacking. The authors present an attempt to make the classification on the basis of hiatuses in the Paleozoic section of the East Baltic area. A hierarchic classification is based on the stratigraphic volume of a hiatus according to which they are divided into giga, macro, meso, micro, nano and pico units. For each of these units a corresponding key has been worked out. It is very convenient to use this method for the depiction of different hiatuses in the stratigraphical scheme. It also enables later to make a principally similar classification of sedimentary breaks the main parameter of which is time - the duration of the break.

In the Russian geological literature the same word is used for the break and the actually existing hiatus. This makes the corresponding terminology uncertain and hampers drawing up a satisfactory classification. A suggestion is made to revise it. 